University of Wisconsin Milwaukee

UWM Digital Commons

Freshwater Faculty Articles

Freshwater Sciences (School of)

8-23-2017

\title{
Developmental Methylmercury Exposure Affects Swimming Behavior and Foraging Efficiency of Yellow Perch (Perca flavescens) Larvae
}

Francisco Xavier Mora Zamorano

University of Wisconsin-Milwaukee, fxm@uwm.edu

Rebekah Klinger

University of Wisconsin - Milwaukee, klinglr@uwm.edu

Niladri Basu

McGill University

Jessica Head

McGill University

Cheryl A. Murphy

Michigan State University

See next page for additional authors

Follow this and additional works at: https://dc.uwm.edu/freshwater_facarticles

\section{Recommended Citation}

Mora-Zamorano, F., Klingler, R., Basu, N., Head, J., Murphy, C. A., Binkowski, F. P., . . Carvan, M. J. (2017). Developmental methylmercury exposure affects swimming behavior and foraging efficiency of yellow perch (perca flavescens) larvae.ACS Omega, 2(8), 4870-4877. doi:10.1021/acsomega.7b00227 


\section{Authors}

Francisco Xavier Mora Zamorano, Rebekah Klinger, Niladri Basu, Jessica Head, Cheryl A. Murphy, Frederick P. Binkowski, Jeremy K. Larson, and Michael J. Carvan III 


\section{Developmental Methylmercury Exposure Affects Swimming Behavior and Foraging Efficiency of Yellow Perch (Perca flavescens) Larvae}

Francisco X. Mora-Zamorano, ${ }^{\dagger}$ Rebekah Klingler, ${ }^{\dagger}$ Niladri Basu, ${ }^{\ddagger}$ Jessica Head, $^{\ddagger}$ Cheryl A. Murphy, ${ }^{\S}$ Frederick P. Binkowski, ${ }^{\dagger}$ Jeremy K. Larson, ${ }^{\dagger}$ and Michael J. Carvan, III ${ }^{*} \dagger$ (0)

${ }^{\dagger}$ School of Freshwater Sciences, University of Wisconsin at Milwaukee, 600 E Greenfield Avenue, Milwaukee, Wisconsin 53204, United States

${ }^{\ddagger}$ Department of Natural Resource Sciences, McGill University, 845 Sherbrooke Street W, Sainte-Anne-de-Bellevue, Quebec H9X 3V9, Canada

${ }^{\S}$ Department of Fisheries and Wildlife, Michigan State University, 220 Trowbridge Road, East Lansing, Michigan 48824, United States

\section{Supporting Information}

ABSTRACT: Methylmercury $(\mathrm{MeHg})$ is a pervasive and ubiquitous environmental neurotoxicant within aquatic ecosystems, known to alter behavior in fish and other vertebrates. This study sought to assess the behavioral effects of developmental $\mathrm{MeHg}$ exposure on larval yellow perch (Perca flavescens) - a nonmodel fish species native to the Great Lakes. Embryos were exposed to $\mathrm{MeHg}(0,30,100,300$, and $1000 \mathrm{nM}$ ) for $20 \mathrm{~h}$ and then reared to 25 days post fertilization (dpf) for analyses of spontaneous swimming, visual motor response (VMR), and foraging efficiency. $\mathrm{MeHg}$ exposures rendered total mercury $(\mathrm{THg})$ body burdens of $0.02,0.21$, $0.95,3.14$, and $14.93 \mu \mathrm{g} / \mathrm{g}$ (wet weight). Organisms exposed to $1000 \mathrm{nM}$ exhibited high mortality; thus, they were excluded from downstream behavioral analyses. All $\mathrm{MeHg}$ exposures tested were associated with a reduction in spontaneous swimming at 17 and $25 \mathrm{dpf}$. Exposure to 30 and $100 \mathrm{nM} \mathrm{MeHg}$ caused altered locomotor output during the VMR assay at $21 \mathrm{dpf}$, whereas exposure to $100 \mathrm{nM} \mathrm{MeHg}$ was associated with decreased foraging efficiency at $25 \mathrm{dpf}$. For the sake of comparison, the secondlowest exposure tested here rendered a THg burden that represents the permissible level of consumable fish in the United States. Moreover, this dose is reported in roughly two-thirds of consumable fish species monitored in the United States, according to the Food and Drug Administration. Although the THg body burdens reported here were higher than expected in the environment, our study is the first to analyze the effects of $\mathrm{MeHg}$ exposure on fundamental survival behaviors of yellow perch larvae and advances in the exploration of the ecological relevance of behavioral end points.

\section{INTRODUCTION}

Mercury $(\mathrm{Hg})$ is a widespread and pervasive neurotoxicant that has been found to affect the behavior of all vertebrates studied to date, including fish. ${ }^{1} \mathrm{Hg}$ contamination affects numerous aquatic ecosystems worldwide; ${ }^{2}$ among these, the Great Lakes Basin has been afflicted by widespread $\mathrm{Hg}$ contamination that has adversely affected the aquatic resources of the region. ${ }^{3}$ Naturally occurring processes, such as volcanic eruption, can release inorganic mercury into the atmosphere, but it was the onset of the industrial revolution that introduced new sources of anthropogenic $\mathrm{Hg}$ emissions, such as fuel combustion, waste incinerators, mining, and manufacturing. Among all of the sources of $\mathrm{Hg}$, the most numerous and largest emitters are coalfired power plants. ${ }^{3}$ This contaminant enters the aquatic ecosystems primarily through atmospheric deposition, ${ }^{4}$ after which microorganisms convert the elemental $\mathrm{Hg}$ into organic

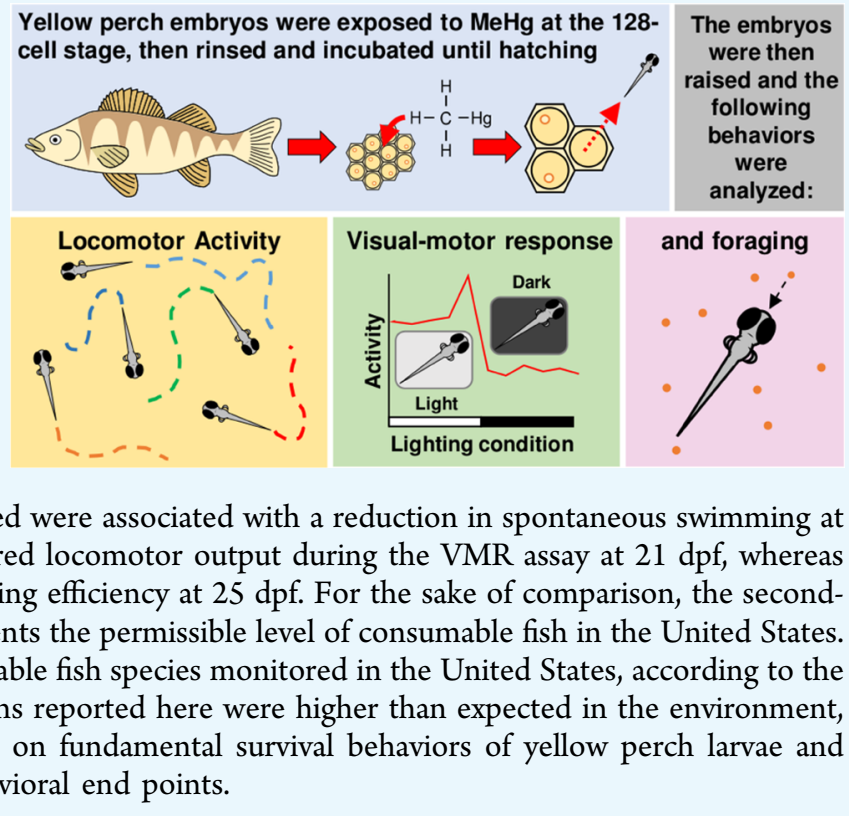

Hg. ${ }^{5}$ Methylmercury $(\mathrm{MeHg}$ ) is reported to be the most abundant organic form of $\mathrm{Hg}$ and accounts for nearly all (9599\%) of the total $\mathrm{Hg}$ fraction in fish tissues. ${ }^{6}$ The U.S. Food and Drug Administration (FDA) monitors nationwide $\mathrm{THg}$ levels in fish and establishes $\mathrm{MeHg}$ concentration thresholds for human consumption; however, relatively little effort is made to investigate the exposure thresholds at which piscivorous fish and their offspring are adversely affected. The Wisconsin Department of Natural Resources (WIDNR) has been monitoring $\mathrm{Hg}$ in freshwater fish since the early 1970s. Despite a reported slow reduction in the tissue burden of $\mathrm{MeHg}$ in fish, the prevalence of fish (e.g., yellow perch [Perca flavescens])

Received: March 23, 2017

Accepted: July 25, 2017

Published: August 23, 2017 
Yellow perch MeHg exposures
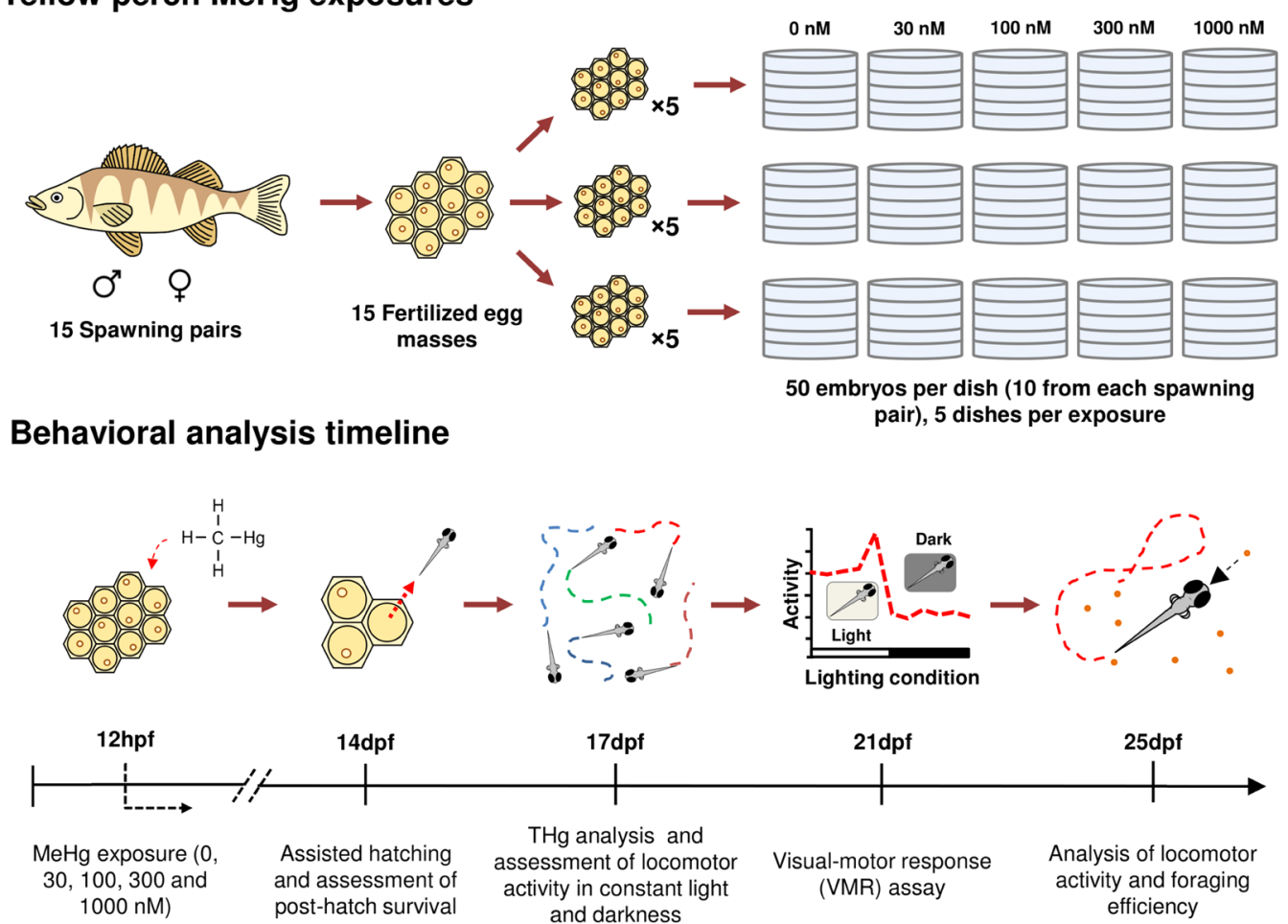

Figure 1. MeHg exposures and behavioral analysis timeline. Fertilized egg masses were collected from 15 sexually mature yellow perch spawning pairs. Three biological replicates consisted of the newly fertilized eggs from five egg masses. At $\sim 12 \mathrm{hpf}$ (128 cell stage), the embryos were exposed to five nominal concentrations of $\mathrm{MeHg}(0,30,100,300$, and $1000 \mathrm{nM})$. At $14 \mathrm{dpf}, \mathrm{THg}$ analysis was performed and posthatch survival was assessed. At $17 \mathrm{dpf}$, the locomotor activity of larvae was assessed in continuous light and continuous darkness. At $21 \mathrm{dpf}$, the larvae were subjected to the VMR assay. Finally, at $25 \mathrm{dpf}$, the locomotor activity of the larvae was once again assessed (only in continuous light), followed by an assessment of foraging efficiency.

consumption advisories in almost every body of water in the Great Lakes region remains an ecological and public health concern. ${ }^{7}$

Concentrations of $\mathrm{Hg}$ in the yellow perch within the Great Lakes Basin vary substantially, with the highest concentrations reported in fish from inland lakes. ${ }^{8,9}$ It has been estimated that yellow perch begin experiencing adverse health effects at a tissue concentration threshold of $0.2 \mu \mathrm{g} / \mathrm{g}$ total mercury (THg; wet weight measured in whole-body samples). ${ }^{7,10} \mathrm{~A}$ recent report by Wiener and collaborators ${ }^{7}$ consolidates $\mathrm{THg}$ concentration data from different yellow perch tissues obtained from 691 bodies of water scattered throughout the Great Lakes region. Average whole-body $\mathrm{THg}$ concentrations in yellow perch from 45 (6.5\%) of these 691 waters equaled or exceeded the aforementioned $0.2 \mu \mathrm{g} / \mathrm{g}$ wet weight threshold. However, if the maximum whole-body $\mathrm{THg}$ concentrations from all of the surveyed sites are considered, $151(22 \%)$ of the sites presented cases that equaled or exceeded $0.2 \mu \mathrm{g} / \mathrm{g}$, some reaching up to $2.60 \mu \mathrm{g} / \mathrm{g}$ in muscle tissue.

Yellow perch play an important role in the near-shore ecology of Lake Michigan ${ }^{11}$ and are popular among recreational fishermen. However, the commercial fishery for yellow perch in Wisconsin waters of Lake Michigan has been closed since 1996 due to a decline in population. Since then, the populations of this important natural resource in Lake Michigan have continued to decrease considerably. Wilber and collaborators ${ }^{11}$ estimated a decline of $92 \%$ of the stock of adult yellow perch in the state of Wisconsin, a species that before 1997 represented $85 \%$ of the recreational catch by number.
The decline of the yellow perch has been attributed mostly to overfishing $^{12}$ and the introduction of invasive species. ${ }^{13}$ However, recent research suggests that developmental $\mathrm{MeHg}$ exposure can alter the behavior of embryonic fathead minnow $^{14,15}$ (Pimephales promelas) and larval zebrafish ${ }^{1}$ (Danio rerio), two model fish species. Ultimately, subtle alterations in behavior may adversely impact fish survival through a process termed "ecological death", ${ }^{16}$ whereby critical survival behaviors of fish (e.g., foraging, predator avoidance, and reproduction) become impaired. In turn, these impairments could also affect population dynamics in the long term, as has been predicted by individual-based adverse outcome pathway models of $\mathrm{MeHg}$ exposure in Atlantic croaker. ${ }^{17}$

Knowledge of how subtle behavioral changes driven by developmental $\mathrm{MeHg}$ exposure may affect the survival of yellow perch, a nonmodel fish species, is severely lacking. An improved understanding of this interaction is required for fisheries and policy makers to consider the broader implications of $\mathrm{MeHg}$ exposure on fish within the Great Lakes Basin and beyond. The objective of the current study was to elucidate the effects of $\mathrm{MeHg}$ exposure on the behavior (i.e., visual motor response (VMR), spontaneous swimming, and foraging efficiency) of yellow perch larvae. Visual motor response, spontaneous swimming, and foraging efficiency assays were chosen to evaluate the possible behavioral effects of developmental exposure of yellow perch to $\mathrm{MeHg}$ based on our previous zebrafish study. ${ }^{1}$ These assays analyze the locomotor responses of organisms to light, evaluate swimming behavior (e.g., total distance traveled and average speed), and quantify prey items captured per unit of time (i.e., foraging efficiency). The 
aforementioned are standard end points for behavioral screening, although foraging efficiency is seldom studied. Larvae were chosen for this study due to the higher sensitivity of developing organisms to environmental insults, such as $\mathrm{MeHg}$ exposure. ${ }^{18}$ Food limitation is suspected to be one of the main causes of larval fish mortality in nature; ${ }^{19}$ thus, a focus of the current study was to investigate a potential link between developmental $\mathrm{MeHg}$ exposure, locomotor output, and foraging efficiency. MeHg-induced behavioral alteration may impact the ability of larvae to successfully forage for prey. Moreover, altered visual motor response and/or locomotion could make larvae more susceptible to predation. ${ }^{17}$ Establishing the links between these end points and toxicant exposure is critical in the development and implementation of bioassays intended to estimate ecological risk (Figure 1).

\section{RESULTS}

Embryo Posthatch Survival and Dosimetry. The wholebody $\mathrm{THg}$ burdens in embryos from the different $\mathrm{MeHg}$ exposures $(0,30,100,300$, and $1000 \mathrm{nM})$ ranged from 0.01 to $14.93 \mu \mathrm{g} / \mathrm{g}$ and were all statistically different from each other $(n$ $=3$ pools of ten 17 dpf larvae, $F_{(3,7)}=55.717, P<0.001$; Table 1). $\mathrm{MeHg}$ exposure at $1000 \mathrm{nM}$ caused a significant decrease in

Table 1. Total Mercury (THg) Burdens and Posthatch Survival of MeHg-Exposed 14 dpf Yellow Perch*

$\begin{array}{llc}\begin{array}{c}\text { nominal MeHg exposure } \\ \text { concentration }(\mathrm{nM})\end{array} & \begin{array}{c}\text { THg in whole } \\ \text { embryo tissue } \\ (\mu \mathrm{g} / \mathrm{g})^{* * *}\end{array} & \begin{array}{c}\text { posthatch survival } \\ \text { (live embryos/dish) })^{* * *}\end{array} \\ 0 & 0.02 \pm 0.01^{\mathrm{a}} & 57.33 \pm 3.48^{\mathrm{a}} \\ 30 & 0.21 \pm 0.11^{\mathrm{b}} & 53.27 \pm 1.94^{\mathrm{a}} \\ 100 & 0.95 \pm 0.12^{\mathrm{c}} & 50.53 \pm 2.94^{\mathrm{a}} \\ 300 & 3.14 \pm 0.67^{\mathrm{d}} & 50.00 \pm 3.32^{\mathrm{a}} \\ 1000 & 14.93 \pm 2.68^{\mathrm{e}} & 25.33 \pm 3.36^{\mathrm{b}} \\ \text { ANOVA } & & \\ \quad F & 55.717 & 16.996 \\ \quad P & <0.001 & <0.001\end{array}$

* Superscript letters denote multiple pairwise comparisons. ${ }^{* *}$ Values expressed as mean $\pm \mathrm{SD}$. ${ }^{* * * *}$ Values expressed as mean $\pm \mathrm{SE}$.

posthatch survival $\left(n=15\right.$ culture dishes, $F_{(4,70)}=16.996, P<$ 0.001; Table 1); thus, this cohort was excluded from downstream behavioral analyses, as stated in Materials and Methods. No deformities were identified in any of the surviving embryos.

Analysis of Swimming Behavior in 17 dpf Larval Yellow Perch. In the light, all MeHg-exposed larvae exhibited lower locomotor activity relative to control $(n=90$ larvae, $F_{(3,156)}=46.162, P<0.001$; Figure 2). However, no statistical differences were observed between exposure groups recorded in the dark $(P>0.05)$. Within each individual exposure group, larvae exhibited higher locomotor activity in the light relative to the dark $(n=90$ larvae, $P<0.001$; Figure 2$)$.

Analysis of the Visual Motor Response in $21 \mathrm{dpf}$ Larval Yellow Perch. During the last light period of the VMR assay, the $30 \mathrm{nM} \mathrm{MeHg-exposed} \mathrm{larvae} \mathrm{exhibited} \mathrm{greater}$ locomotor activity than the $100 \mathrm{nM} \mathrm{MeHg}$ exposure groups ( $n$ $=36$ larvae, $F_{(3,140)}=5.081, P<0.001$; Figure 3A). Comparison of all other exposure groups within the other light and dark periods yielded no significant difference $(n=36$ larvae, $P>$ 0.05 , Figure $3 \mathrm{~A}$ ). Moreover, when comparing the locomotor output of the larvae throughout the $50 \mathrm{~min}$ duration of the

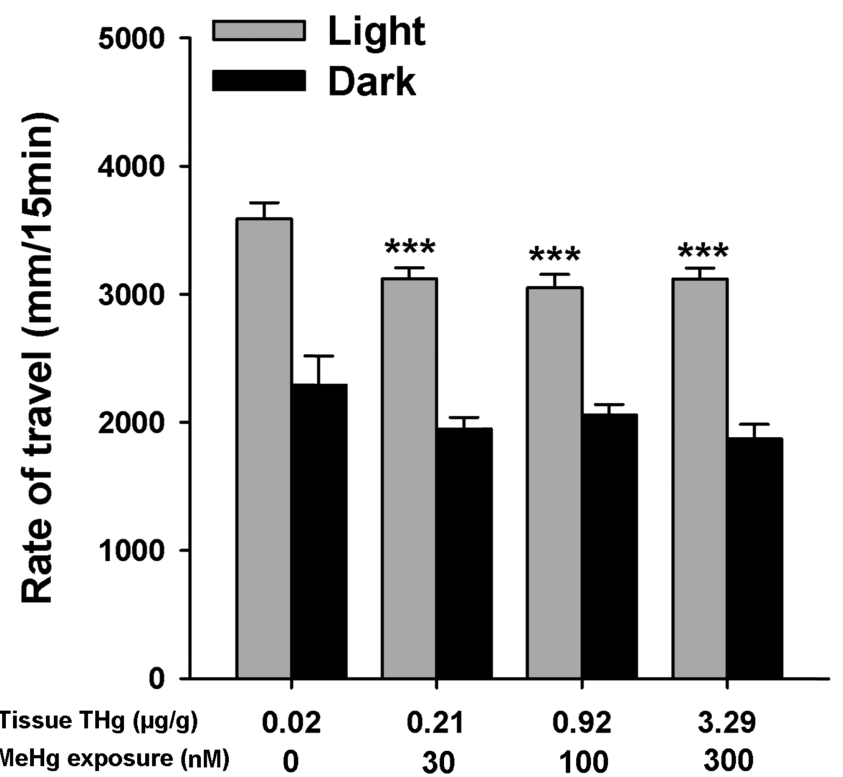

Figure 2. Locomotor activity of $17 \mathrm{dpf}$ yellow perch exposed to graded concentrations of $\mathrm{MeHg}$ and tested in two different lighting conditions. Yellow perch of all exposure groups tested in the light exhibited a higher locomotor activity compared to the groups tested in the dark $(n=15$ plates, $P<0.001)$. Overall, all MeHg-exposed larvae exhibited lower locomotor activity in the light $(n=15$ plates, $* * * P<$ $0.001)$. However, no statistical differences were observed between exposure groups recorded in the dark $(n=15$ plates, $P=0.163)$. Values are expressed as mean $\pm \mathrm{SE}$.

whole experiment, the locomotor activity of larvae exposed to $30 \mathrm{nM} \mathrm{MeHg}$ was higher than that of the controls $(n=36$ larvae, $F_{(3,140)}=7.525, P<0.001$; Figure 3B). In contrast, larvae exposed to $100 \mathrm{nM} \mathrm{MeHg}$ exhibited reduced locomotor activity relative to control ( $n=36$ larvae, $P<0.001$; Figure 3B). There was no statistical difference between the $300 \mathrm{nM} \mathrm{MeHg}$ exposure group and the control $(n=36$ larvae, $P>0.05$; Figure 3B).

Spontaneous Swimming and Foraging Efficiency at 25 dpf. As observed at $17 \mathrm{dpf}$, the larvae from all $\mathrm{MeHg}$ exposure groups continued to exhibit decreased locomotor activity (i.e., total distance traveled in $30 \mathrm{~s}$ and \% of time active [\% activity]) at $25 \mathrm{dpf}$ compared to control. The greatest decrease in locomotor activity (relative to the control) was observed in the $100 \mathrm{nM} \mathrm{MeHg}$ exposure group ( $n=120$ larvae, $F_{(3,476)}=5.146, P<0.05$; Table 2$)$. No effects were observed in the linearity of the trajectories (NGDR) during the $30 \mathrm{~s}$ analysis periods $(n=120$ larvae, $P>0.05$; Table 2$)$. Similar to the locomotor activity results, the foraging efficiency was reduced in all $\mathrm{MeHg}$ exposure groups, compared to control, but statistical significance was observed only in the $100 \mathrm{nM} \mathrm{MeHg}$ exposure group ( $n=4$ groups of larvae, $F_{(3,12)}=4.095, P<0.05$, Table 2).

\section{DISCUSSION}

Our study elucidated the effects of embryonic $\mathrm{MeHg}$ exposure on the posthatch survival, spontaneous swimming, VMR, and foraging efficiency of larval yellow perch. The $\mathrm{MeHg}$ exposures analyzed herein ranged from an exposure concentration that rendered a THg body burden of $0.21 \mu \mathrm{g} / \mathrm{g}$ (wet weight; $30 \mathrm{nM}$ $\mathrm{MeHg}$ [lowest exposure concentration]) to an exposure that resulted in a THg burden of $14.93 \mu \mathrm{g} / \mathrm{g}$ (wet weight; $1000 \mathrm{nM}$ $\mathrm{MeHg}$ [highest exposure concentration]), which caused a 

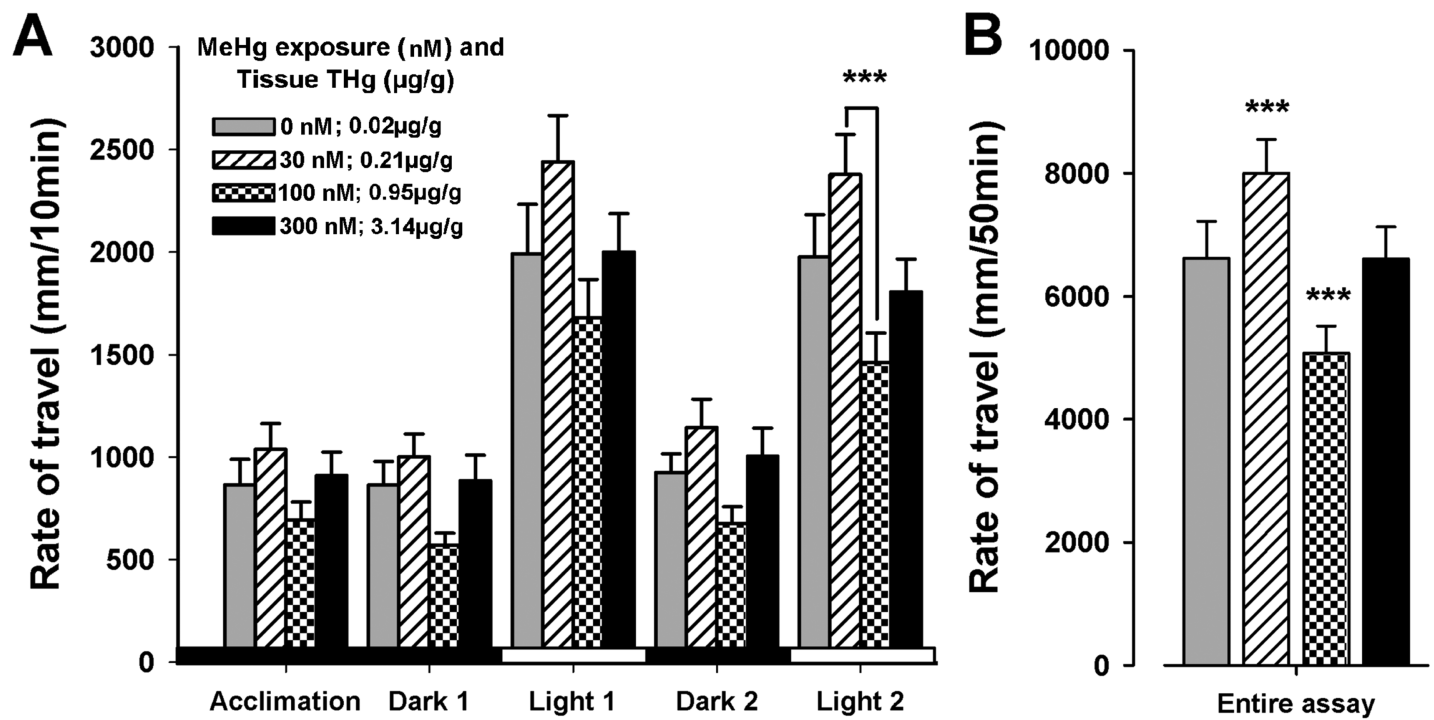

Phases of the VMR assay

Figure 3. Locomotor output of $21 \mathrm{dpf}$ yellow perch during the VMR assay. (A) During the last light period of the VMR assay, larvae exposed to 30 $\mathrm{nM} \mathrm{MeHg}$ swam significantly more often than those exposed to $100 \mathrm{nM} \mathrm{MeHg}(n=36$ larvae, $* * * P<0.001)$. (B) Throughout the duration of the entire $50 \mathrm{~min}$ assay, the locomotor activity of larvae exposed to $30 \mathrm{nM} \mathrm{MeHg}$ was higher than that of control $(n=36$ larvae, $P<0.001)$, and larvae exposed to $100 \mathrm{nM} \mathrm{MeHg}$ swam significantly less often than control $(n=36$ larvae, $P<0.001)$. There was no difference between the $300 \mathrm{nM} \mathrm{MeHg}$ exposed and control groups $(n=36$ larvae, $P=0.959)$. Values are expressed as mean $\pm \mathrm{SE}$.

Table 2. Locomotor Activity and Foraging Efficiency of 25 dpf Yellow Perch*

\begin{tabular}{|c|c|c|c|c|}
\hline $\mathrm{THg}$ in whole embryo tissue $(\mu \mathrm{g} / \mathrm{g})^{* *}$ & total distance traveled ( $\mathrm{mm}$ in $30 \mathrm{~s})$ & $\%$ activity & net-to-gross displacement ratio & foraging efficiency $^{* *}$ \\
\hline 0.02 & $126.13 \pm 11.27^{\mathrm{a}}$ & $30.41 \pm 0.02^{\mathrm{a}}$ & $0.34 \pm 0.02^{\mathrm{a}}$ & $101.75 \pm 17.84^{\mathrm{a}}$ \\
\hline 0.21 & $98.13 \pm 8.14^{b}$ & $23.81 \pm 0.01^{b}$ & $0.35 \pm 0.02^{\mathrm{a}}$ & $74.75 \pm 20.35^{\mathrm{a}}$ \\
\hline 0.95 & $82.49 \pm 5.81^{b}$ & $22.69 \pm 0.01^{b}$ & $0.41 \pm 0.02^{\mathrm{a}}$ & $26.00 \pm 32.79^{b}$ \\
\hline 3.14 & $90.84 \pm 7.11^{b}$ & $23.87 \pm 0.01^{b}$ & $0.38 \pm 0.02^{\mathrm{a}}$ & $59.75 \pm 45.72^{\mathrm{a}}$ \\
\hline \multicolumn{5}{|l|}{ ANOVA } \\
\hline$F$ & 5.146 & 6.435 & 2.593 & 4.095 \\
\hline$P$ & 0.002 & $<0.001$ & 0.052 & 0.032 \\
\hline
\end{tabular}

*Superscript letters denote statistical differences relative to control. Values expressed as mean \pm SE. *** Foraging efficiency was defined as the number of Artemia nauplii consumed in $10 \mathrm{~min}$ per group of 30 yellow perch larvae.

dramatic decrease in posthatch survival. All $\mathrm{MeHg}$ exposures tested in this study were associated with a reduction in spontaneous swimming at 17 and $25 \mathrm{dpf}$; two exposures (30 and $100 \mathrm{nM}$ ) altered locomotor output during the VMR assay at $21 \mathrm{dpf}$. The $100 \mathrm{nM} \mathrm{MeHg}$ exposure was also associated with decreased foraging efficiency at $25 \mathrm{dpf}$. Interestingly, the second-lowest $\mathrm{MeHg}$ concentration tested (30 nM; yielded neurobehavioral effects on perch) in our study rendered $\mathrm{THg}$ burdens $(0.95 \pm 0.12 \mu \mathrm{g} / \mathrm{g}[$ mean $\pm \mathrm{SEM}])$ that represent the FDA-established threshold for $\mathrm{MeHg}$ concentration in seafood intended for human consumption $(1 \mu \mathrm{g} / \mathrm{g}$; https://www.atsdr. cdc.gov/toxfaqs $/$ tf.asp?id=113\&tid=24). Moreover, this tissue burden is found in roughly two-thirds of commercial fish species monitored by the FDA (https://www.fda.gov/Food/ FoodborneIllnessContaminants/Metals/ucm115644.htm).

The lowest exposure of $\mathrm{MeHg}(30 \mathrm{nM})$ included in our experimental paradigm resulted in an embryo body burden that corresponds to the estimated threshold of $0.2 \mu \mathrm{g} / \mathrm{g} \mathrm{MeHg}$, at which adult yellow perch begin to exhibit adverse effects in behavior. ${ }^{7}$ Moreover, in a study by Hammerschmidt and collaborators, $^{20}$ the highest reported $\mathrm{MeHg}$ burden in wild caught yellow perch embryos from an inland lake in Wisconsin was found to be $819 \mathrm{ng} / \mathrm{g}$ dry weight (approximately $0.12 \mu \mathrm{g} / \mathrm{g}$ wet weight), which is roughly half of what was observed in the lowest $\mathrm{MeHg}$ exposure in this study. This highlights the fact that the observed concentrations of $\mathrm{THg}$ in the tissue of yellow perch in this study were relatively high. However, body burdens of $\mathrm{THg}$ that exceed environmental relevance provide pertinent preliminary evidence toward elucidation of the dose-dependent effects of $\mathrm{MeHg}$ exposure on larval yellow perch. Our study is the first to expose yellow perch embryos to $\mathrm{MeHg}$ under laboratory controlled conditions and measure THg burdens in tissues of larvae as a function of $\mathrm{MeHg}$ exposure concentrations, thus establishing precedence for further studies. Notably, since we observed effects in the lowest $\mathrm{MeHg}$ exposure group, it is likely that effects could be observed at lower concentrations. Additional experiments with lower $\mathrm{MeHg}$ exposure concentrations are required to confirm this possibility.

To date, the majority of studies concerned with the study of behavior in fish have been conducted using well-established model fish species, such as the zebrafish (Danio rerio), Japanese medaka (Oryzias latipes), goldfish (Carassius auratus), and fathead minnows (Pimephales promelas). ${ }^{1,14,15,21-23}$ Here, we made use of the established methods of behavioral analysis developed in the aforementioned model organisms to assess behavior in yellow perch-a nonmodel organism. The 
behavioral end points investigated here were selected to span different levels of complexity, from fundamental behaviors (i.e., spontaneous swimming) to complex responses to visual stimuli (i.e., VMR) and predator-prey interactions (i.e., foraging efficiency). Spontaneous locomotor activity is by far the most prominently documented behavioral end point that can be plausibly linked to more complex behaviors, such as foraging; ${ }^{24}$ thus, our study sought to establish the relationship between these end points in MeHg-exposed yellow perch larvae. Moreover, the VMR assay was employed as an integral diagnostic tool to assess the reactivity of the larvae to abrupt visual cues, which engages both visual perception and a locomotor output as a reaction. This assay has been used in laboratory fish as a screening tool for neuroactive compounds, ${ }^{25}$ and it has been adopted by the United States Environmental Protection Agency to screen for neurotoxicants ${ }^{26}$ due to its robustness and reliability. In the present study, the ecological value of the aforementioned end points was explored.

The first set of behavioral experiments performed using 17 dpf yellow perch aimed to identify $\mathrm{MeHg}$-mediated effects on baseline swimming behavior. These experiments revealed a decrease in locomotor activity in all $\mathrm{MeHg}$-exposed yellow perch tested in constant light. These results contrasted with those observed in $7 \mathrm{dpf}$ zebrafish, whereby all $\mathrm{MeHg}$ exposures resulted in increased locomotor activity. ${ }^{1}$ These observations underline the importance of conducting comparative assays between model and nonmodel organisms, as identical assays and similar $\mathrm{MeHg}$ exposures resulted in opposite behavioral responses in the two fish species.

To account for the possible effects of illumination on the activity of yellow perch, a spontaneous swimming experiment was conducted in the presence and absence of light. Our results revealed not only that yellow perch are significantly more active in the presence of light than in the dark, but also that behavioral effects of $\mathrm{MeHg}$ were only noticeable in a well-lit observation chamber, when the fish were more active. The overall lower locomotion of yellow perch in a dark environment appeared to mask any of the behavioral effects of $\mathrm{MeHg}$ that are otherwise observed in the presence of light.

When analyzing the VMR, yellow perch exhibited higher locomotor activity in the light than in the dark, which contrasts with what has been described previously in zebrafish. ${ }^{27}$ This response is presumably due to the strong phototactic behavior of yellow perch early in development. Phototaxis was observed regularly in our experimental organisms; the larvae would consistently congregate toward the light of a flashlight used during the daily media changes. This being said, it could be argued that despite the differences in the way the two fish species react to light, they both exhibit a VMR.

There were no statistically significant effects of $\mathrm{MeHg}$ exposure on the locomotor activity of yellow perch throughout each of the $10 \mathrm{~min}$ intervals of the VMR assay. However, differences were identified in the locomotor activity of the 21 dpf MeHg-exposed yellow perch throughout the duration of the whole experiment. This approach identified hyperactivity in larvae exposed to $30 \mathrm{nM} \mathrm{MeHg}$ and hypoactivity in larvae exposed to $100 \mathrm{nM} \mathrm{MeHg}$. Increases in locomotion in the 30 $\mathrm{nM}$ exposure group were unexpected because we did not observe hyperactivity in any other experiment in this study. This result suggests that increased locomotion in larval yellow perch exposed to $30 \mathrm{nM} \mathrm{MeHg}$ during the VMR assay could be specifically linked to an increased excitability to visual stimuli.
The swimming and foraging efficiency experiments using 25 dpf larvae were done consecutively to assess if there was a relationship between locomotor output and prey capture. All $\mathrm{MeHg}$-exposed individuals tested in the spontaneous swimming experiment exhibited lower locomotor output, as had been observed in $17 \mathrm{dpf}$ larvae. Furthermore, foraging efficiency was only significantly reduced in $100 \mathrm{nM} \mathrm{MeHg}$-exposed larvae. Interestingly, this same exposure group performed poorly in the VMR assay, suggesting that this assay could have value as a diagnostic tool to predict behavioral abnormalities later in development.

Remarkably, few studies have linked environmental toxicant exposure with impaired foraging behavior of larval fish, most of which were completed by a single research group that has focused on the effects of $\mathrm{MeHg}$ in killifish (Fundulus heteroclitus); ${ }^{28,29}$ other studies have performed embryonic $\mathrm{MeHg}$ exposures in fish, but only elucidated foraging impairments at the onset of adulthood. ${ }^{30}$ Although all MeHgexposed yellow perch larvae appeared to have an overall reduction in foraging, a statistically significant reduction was observed in the $100 \mathrm{nM} \mathrm{MeHg}$ exposure group, but not in organisms exposed to $300 \mathrm{nM}$. Yellow perch are known to be notably resistant to heavy metal exposure; ${ }^{31}$ thus, it is possible that exposures to higher concentrations of $\mathrm{MeHg}$ may have caused mortality among the most $\mathrm{MeHg}$-sensitive organisms, thus shifting this exposure group to a more $\mathrm{MeHg}$-tolerant cohort. Our observations of lower foraging efficiency in $100 \mathrm{nM}$ $\mathrm{MeHg}$-exposed embryos correspond to a decreased locomotor activity observed at 17,21 , and $25 \mathrm{dpf}$. This positive relationship between locomotor activity and foraging activity was also observed in our zebrafish study; ${ }^{1}$ however, in the said study, $\mathrm{MeHg}$ exposure caused an increase in locomotor activity and foraging efficiency in zebrafish larvae. The direct waterborne $\mathrm{MeHg}$ exposure of zebrafish embryos, per procedures analogous to those in the present yellow perch study, also caused hyperactivity. ${ }^{32}$ These differences in behavioral outcomes may be attributable to not only the inherent distinctions between species but also exposure duration and critical windows of exposures during development. These observations underline the current difficulties of estimating the effects of environmental contaminants on nonmodel organisms on the basis of data collected from model organisms; thus, an effort must be made to match experimental conditions when analyzing behavioral end points in different species of organisms. Moreover, it is important to recognize the need to diversify our understanding of the subtle (i.e., nonlethal) effects of environmental contaminants on end points that can be easily placed in an ecological context (i.e., foraging and predator avoidance) to facilitate the assessment of ecological risk on the basis of laboratory-derived toxicity assays.

Our results confirm the notion of a positive relationship between locomotor output and prey capture, which is a common assumption when creating simulation models of predator-prey interaction. ${ }^{17}$ This notion held true for our observations of hypoactivity coupled with decreased foraging in yellow perch larvae, as well as our previous observations of increased locomotion and increased foraging efficiency in zebrafish. ${ }^{1}$ Although the THg embryo burdens yielded in the current study were higher than expected in nature, our study is the first to investigate the effects of $\mathrm{MeHg}$ on relevant survival behaviors of yellow perch larvae, thus establishing a precedence for the assessment of the potentially harmful effects of toxic compounds on this ecologically relevant species. 


\section{MATERIALS AND METHODS}

The procedures for the rearing of yellow perch embryos, $\mathrm{MeHg}$ exposure, and behavioral analysis are described below and summarized in Figure 1. All behavioral analyses were conducted from 12:00 pm to 7:00 pm to limit the effects of circadian rhythms. $^{27}$

Embryo Procurement, Methylmercury Exposure, and Dosimetry. All protocols for the care and handling of yellow perch were approved by the Institutional Animal Care and Use Committee (IACUC) of the University of Wisconsin at Milwaukee (Milwaukee, WI). Egg masses were obtained from sexually mature yellow perch kept as a broodstock in the Great Lakes Aquaculture Center (School of Freshwater Sciences, University of Wisconsin at Milwaukee). The eggs were collected from 15 pairwise breedings, whereby the egg mass from each female was fertilized with the sperm of randomly selected males. The fertilized eggs were kept in a cooler at 10 ${ }^{\circ} \mathrm{C}$ at all times. The 15 fertilized egg masses were then divided into three biological replicates, each one incorporating eggs from five different spawning pairs; all experiments described hereafter were conducted with these three replicate sets of fertilized eggs.

When spawning, female yellow perch extrude up to 40000 eggs into a long and continuous "accordion-folded" strand that is $4-5 \mathrm{~cm}$ thick and approximately a meter long. ${ }^{33,34}$ The egg masses were cut into small ribbons containing roughly 10 fertilized eggs each. A total of five ribbons (one from each spawning pair) were placed in a metal-free, plastic culture dish (100 mm diameter $\times 15 \mathrm{~mm}$ depth) containing $50 \mathrm{~mL}$ of E2 embryo medium ( $15 \mathrm{mM} \mathrm{NaCl}, 0.5 \mathrm{mM} \mathrm{KCl}, 1 \mathrm{mM} \mathrm{MgSO}{ }_{4}$, $150 \mu \mathrm{M} \mathrm{KH}_{2} \mathrm{PO}_{4}, 50 \mu \mathrm{M} \mathrm{Na}_{2} \mathrm{HPO}_{4}, 1 \mathrm{mM} \mathrm{CaCl}$, and $0.7 \mathrm{mM}$ $\mathrm{NaHCO}_{3}$ ). A total of 3750 embryos were reared ex vivo, accounting for 3 biological replicates, $5 \mathrm{MeHg}$ exposure concentrations, and 5 culture dishes per exposure group with each containing 50 embryos (Figure 1). Immediately after distributing the egg ribbons into culture dishes, the developing embryos had reached the 128-cell stage $(\sim 12 \mathrm{~h}$ post fertilization [hpf]). At this point, the E2 medium of each culture dish was removed and quickly replaced with $50 \mathrm{~mL}$ of MeHg-contaminated E2 medium (0, 30, 100, 300, and 1000 $\mathrm{nM}[0,0.006,0.022,0.065$, and $0.216 \mathrm{ppm}$, respectively]; $0.033 \%$ ethanol was used as a vehicle in all solutions including control), as previously described. ${ }^{35,36}$ This direct exposure method using newly fertilized embryos is intended to mimic the maternal transfer of $\mathrm{MeHg}$ to the offspring and is a common exposure procedure for chemical toxicity assays in zebrafish embryos. ${ }^{32,37}$ The yellow perch embryos remained in the exposure solutions incubated at $10{ }^{\circ} \mathrm{C}$ for $20 \mathrm{~h}$, after which all dishes were rinsed three times with fresh $10{ }^{\circ} \mathrm{C}$ E2 medium to stop any further $\mathrm{MeHg}$ exposure. Once the eggs were thoroughly rinsed, they were kept in fresh E2 medium and returned to the incubator; the E2 medium was exchanged daily. The incubation of the embryos was initiated at the temperature of $10{ }^{\circ} \mathrm{C}$ (as stated above) and progressively increased by $1{ }^{\circ} \mathrm{C}$ every second day until a final temperature of $20{ }^{\circ} \mathrm{C}$ was attained.

At $14 \mathrm{dpf}$, the embryos were assisted to hatch by vigorously pipetting them using a $25 \mathrm{~mL}$ pipette. Chorion debris and dead embryos were removed from each culture dish, and live embryos were immediately counted. The embryos developmentally exposed to $1000 \mathrm{nM} \mathrm{MeHg}$ exhibited a significant decrease in posthatch survival at $14 \mathrm{dpf}$; thus, this cohort was excluded from the behavioral analyses (Table 1). Upon initiation of spontaneous swimming at $17 \mathrm{dpf}$, pools of 10 randomly selected individuals per exposure group (0, 30, 100, and $300 \mathrm{nM}$ ) were flash-frozen in liquid nitrogen (in triplicate) and stored for later analysis of $\mathrm{THg}$. $\mathrm{THg}$ contents in whole embryo tissues were analyzed on a wet weight basis using a Direct Mercury Analyzer 80 (DMA-80; Milestone Inc, Shelton, $\mathrm{CT})$, as described by Basu and collaborators. ${ }^{38}$ Assay performance was deemed acceptable according to U.S. EPA Method 7473 performance criteria guidelines and in consideration of the values measured in the fish samples. Briefly, the detection limit (mean value of blanks plus $3 \times$ the standard deviation of the mean; $n=33$ ) was $0.21 \mathrm{ng}$ total $\mathrm{Hg}$. Analyses $(n=12)$ of a relevant certified reference material (DORM-4, National Research Council of Canada) revealed an analytical accuracy of $102.3 \pm 4.8 \%$ (mean \pm SD) and a precision of 4.7 $\pm 2.6 \%$.

Analysis of Swimming Behavior at $17 \mathrm{dpf}$. Yellow perch larvae initiate swimming at $17 \mathrm{dpf}$ and thus behavioral analyses commenced at this time point. Commonly, the locomotor activity is evaluated both in the dark and in the light to account for any possible effects of illumination on the behavioral responses of the experimental organisms. ${ }^{39}$ Here, we analyzed the spontaneous swimming activity of $17 \mathrm{dpf}$ yellow perch larvae in constant light and constant darkness for $15 \mathrm{~min}$, after a $5 \mathrm{~min}$ acclimation period; experiments in the presence and absence of light were conducted in parallel using different test organisms for each lighting condition (i.e., one group of organisms was assigned to be analyzed in the dark, another was analyzed in the light). Individual larvae were transferred into the wells of a transparent 24-well microtiter plate (Costar; Corning, NY), and their spontaneous swimming activity was evaluated using two DanioVision systems (Noldus Information Technology, Leesburg, VA) to increase throughput. Each plate contained six larvae from each exposure cohort. A total of 15 plates were analyzed per lighting condition $(n=15$ plates analyzed in constant light; $n=15$ plates analyzed in constant darkness). The total distance traveled of each fish was calculated using EthoVision software version 8.0 (Noldus Information Technology).

Analysis of Visual Motor Response at $21 \mathrm{dpf}$. The visual motor response (VMR) assay has been extensively described in the zebrafish as a complex behavioral paradigm that integrates both the visual perception and the locomotion of the fish. ${ }^{40}$ This experiment consists of tracking larva activity and abruptly changing the light intensity in an enclosed observation chamber every $10-20 \mathrm{~min}$. At $21 \mathrm{dpf}$, larvae were transferred to 24-well microtiter plates (as described above in the analysis of $17 \mathrm{dpf}$ larvae). Six 24-well plates were analyzed in total ( $n=36$ larvae per $\mathrm{MeHg}$ exposure). The larvae were acclimated for 10 min in the dark, after which they underwent two cycles of alternating $10 \mathrm{~min}$ light and dark periods for a total of $50 \mathrm{~min}$. Larva activity was evaluated using a DanioVision system and EthoVision software version 8.0, as described above.

Analysis of Swimming Behavior and Foraging Efficiency at $25 \mathrm{dpf}$. At $25 \mathrm{dpf}$, spontaneous swimming was evaluated again prior to the assessment of foraging efficiency. The larvae were analyzed in a custom-made behavior observation chamber, as described in two previous studies. ${ }^{1,32}$ All video recordings were streamed to a remote computer at a resolution of $960 \times 720$ pixels and a frame rate of 30 frames per second (fps) via the MATLAB image acquisition toolbox (The MathWorks, Inc., Natick, MA). 
At 9:00 am on the day of the analysis, thirty $25 \mathrm{dpf}$ larvae were transferred to glass culture dishes $(100 \mathrm{~mm}$ diameter $\times 15$ $\mathrm{mm}$ depth) containing $50 \mathrm{~mL}$ of clean E2 medium $\left(20^{\circ} \mathrm{C}\right)$. The dish was then transferred to the recording chamber, and the larvae were acclimated for $5 \mathrm{~min}$, after which they were recorded for $10 \mathrm{~min}$ to assess spontaneous swimming. A total of 4 culture dishes containing 30 larvae each were recorded per $\mathrm{MeHg}$ exposure ( $n=120$ larvae per exposure). Our laboratory has successfully implemented machine vision algorithms to quantify the behavior of multiple zebrafish larvae in the same arena. ${ }^{1,32}$ However, yellow perch larvae proved to be more challenging to track due to their lack of pigmentation and a tendency to aggregate and remain immotile for long periods of time. Therefore, the locomotor activity of yellow perch larvae was tracked manually with the "Manual Tracking" Image J plugin $^{41,42}$ (Supporting Information, Video S1). A $30 \mathrm{~s}$ fragment was selected from the 10 min videos (from $5 \mathrm{~min}$, $0 \mathrm{~s}$ [5:00] to $5 \mathrm{~min}, 30 \mathrm{~s}[5: 30])$ and then this video was converted from 30 to $6 \mathrm{fps}$ to facilitate manual frame-by-frame analysis of the footage. Total distance traveled ( $\mathrm{mm}$ in $30 \mathrm{~s}$ ), percent of time active (\% activity), and net-to-gross displacement ratio (NGDR) were calculated for each individual larva via a custom Microsoft Excel Macro (Microsoft, Redmond, WA). NGDR is a measurement of trajectory linearity, where displacement is the linear distance between the beginning, the ending point and the gross displacement is the total distance traveled to get from one point to the next, and NGDR that approximated 1 indicates a linear path. ${ }^{17}$ Immediately after the recording of spontaneous swimming, foraging efficiency was evaluated ( $n=4$ groups of 30 larvae) by introducing 5 Artemia nauplii per larva (i.e., 30 larvae per dish, foraging on 150 nauplii) into the culture dish. The larvae were allowed to feed for $10 \mathrm{~min}$, after which the remaining nauplii were manually counted.

Data Processing and Statistical Analysis. Statistical analyses were conducted with SigmaPlot software version 11.0 (Systat Software, San Jose, CA). Measured concentrations of $\mathrm{THg}$ in the embryos were log-transformed prior to statistical analysis via one-way ANOVA due to the 3- to 12-fold differences between exposure groups. Statistical analysis of the spontaneous swimming of $17 \mathrm{dpf}$ larvae exposed to different $\mathrm{MeHg}$ exposures and lighting conditions (i.e., constant light and constant dark) was performed using two-way ANOVA. The VMRs of $21 \mathrm{dpf}$ larvae were analyzed with two-way repeated measures ANOVA. Total distance traveled $(\mathrm{mm}$ in $30 \mathrm{~s}), \%$ activity, NGDR, and foraging efficiency in 25 dpf larvae were analyzed using one-way ANOVA. For all statistically significant results, post hoc multiple pairwise comparisons were performed via the Holm-Sidak method. $P$ $<0.05$ was considered statistically significant in all analyses.

\section{ASSOCIATED CONTENT}

\section{S Supporting Information}

The Supporting Information is available free of charge on the ACS Publications website at DOI: 10.1021/acsomega.7b00227.

Video S1, a representative example of manual tracking of yellow perch spontaneous swimming (AVI)

\section{AUTHOR INFORMATION}

\section{Corresponding Author}

*E-mail: carvanmj@uwm.edu. Tel: +1(414)-382-1700. Fax: +1 (414)-382-1705.

\section{ORCID}

Michael J. Carvan III: 0000-0002-9190-9417

\section{Author Contributions}

The manuscript was written through contributions of all authors. All authors have given approval to the final version of the manuscript.

\section{Funding}

Funding for this study was derived from EPA-GLRI (EPA GLNPO-2010-TX-8-1223-395). Coauthor Cheryl A. Murphy was partially supported by AgBioResearch at Michigan State University.

\section{Notes}

The authors declare no competing financial interest.

\section{ACKNOWLEDGMENTS}

The authors thank Jeff Nuese and Henry Herbert from the Great Lakes Aquaculture Center of the School of Freshwater Sciences (University of Wisconsin at Milwaukee) for their valuable advice regarding good husbandry practices to ensure survival of larval yellow perch. They also thank Gordana Martincevic, Jessica Pawly, and Jenny Eng (Environmental Health Sciences Laboratory, McGill University, Sainte-Annede-Bellevue, Quebec) for analysis of THg in larval yellow perch.

\section{REFERENCES}

(1) Mora-Zamorano, F. X.; Klingler, R.; Murphy, C. A.; Basu, N.; Head, J.; Carvan, M. J., III Parental whole life cycle exposure to dietary methylmercury in zebrafish (Danio rerio) affects the behavior of offspring. Environ. Sci. Technol. 2016, 50, 4808-4816.

(2) Devlin, E. W. Acute Toxicity, Uptake and Histopathology of Aqueous Methyl Mercury to Fathead Minnow Embryos. Ecotoxicology 2006, 15, 97-110.

(3) Monson, B. A. Trend Reversal of Mercury Concentrations in Piscivorous Fish from Minnesota Lakes: 1982-2006. Environ. Sci. Technol. 2009, 43, 1750-1755.

(4) Risch, M. R.; DeWild, J. F.; Krabbenhoft, D. P.; Kolka, R. K.; Zhang, L. Litterfall mercury dry deposition in the eastern USA. Environ. Pollut. 2012, 161, 284-290.

(5) Watras, C. J.; Bloom, N. S. Mercury and methylmercury, in individual zooplankton: Implications for bioaccumulation. Limnol. Oceanogr. 1992, 37, 1313-1318.

(6) Drevnick, P. E.; Sandheinrich, M. B. Effects of dietary methylmercury on reproductive endocrinology of fathead minnows. Environ. Sci. Technol. 2003, 37, 4390-4396.

(7) Wiener, J. G.; Sandheinrich, M. B.; Bhavsar, S. P.; Bohr, J. R.; Evers, D. C.; Monson, B. A.; Schrank, C. S. Toxicological significance of mercury in yellow perch in the Laurentian Great Lakes region. Environ. Pollut. 2012, 161, 350-357.

(8) Harris, R. C.; Bodaly, R. D. Temperature, growth and dietary effects on fish mercury dynamics in two Ontario lakes. Biogeochemistry 1998, 40, 175-187.

(9) Wiener, J. G.; Sandheinrich, M. B.; Bhavsar, S. P.; Bohr, J. R.; Evers, D. C.; Monson, B. A.; Schrank, C. S. Toxicological significance of mercury in yellow perch in the Laurentian Great Lakes region. Environ. Pollut. 2012, 161, 350-357.

(10) Beckvar, N.; Dillon, T. M.; Read, L. B. Approaches for linking whole-body fish tissue residues of mercury or DDT to biological effects thresholds. Environ. Toxicol. Chem. 2005, 24, 2094-2105.

(11) Wilberg, M. J.; Bence, J. R.; Eggold, B. T.; Makauskas, D.; Clapp, D. F. Yellow perch dynamics in southwestern Lake Michigan during 1986-2002. N. Am. J. Fish. Manage. 2005, 25, 1130-1152.

(12) Marsden, J. E.; Robillard, S. R. Decline of Yellow Perch in Southwestern Lake Michigan, 1987-1997. N. Am. J. Fish. Manage. 2004, 24, 952-966. 
(13) Shroyer, S. M.; McComish, T. S. Relationship between Alewife Abundance and Yellow Perch Recruitment in Southern Lake Michigan. N. Am. J. Fish. Manage. 2000, 20, 220-225.

(14) Bridges, K.; Venables, B.; Roberts, A. Effects of dietary methylmercury on the dopaminergic system of adult fathead minnows and their offspring. Environ. Toxicol. Chem. 2017, 36, 1077-1084.

(15) Bridges, K. N.; Soulen, B. K.; Overturf, C. L.; Drevnick, P. E.; Roberts, A. P. Embryotoxicity of maternally-transferred methylmercury to fathead minnows (Pimephales promelas). Environ. Toxicol. Chem. 2016, 35, 1436-41.

(16) Scott, G. R.; Sloman, K. A. The effects of environmental pollutants on complex fish behaviour: integrating behavioural and physiological indicators of toxicity. Aquat. Toxicol. 2004, 68, 369-392.

(17) Alvarez, M. d. C.; Murphy, C. A.; Rose, K. A.; McCarthy, I. D.; Fuiman, L. A. Maternal body burdens of methylmercury impair survival skills of offspring in Atlantic croaker (Micropogonias undulatus). Aquat. Toxicol. 2006, 80, 329-337.

(18) Samson, J. C.; Shenker, J. The teratogenic effects of methylmercury on early development of the zebrafish Danio rerio. Aquat. Toxicol. 2000, 48, 343-354.

(19) von Herbing, I. H.; Gallager, S. M. Foraging behavior in early Atlantic cod larvae (Gadus morhua) feeding on a protozoan (Balanion sp.) and a copepod nauplius (Pseudodiaptomus sp.). Mar. Biol. 2000, 136, 591-602.

(20) Hammerschmidt, C. R.; Wiener, J. G.; Frazier, B. E.; Rada, R. G. Methylmercury content of eggs in yellow perch related to maternal exposure in four Wisconsin lakes. Environ. Sci. Technol. 1999, 33, 9991003.

(21) Kalueff, A. V.; Gebhardt, M.; Stewart, A. M.; Cachat, J. M.; Brimmer, M.; Chawla, J. S.; Craddock, C.; Kyzar, E. J.; Roth, A.; Landsman, S.; et al. Towards a comprehensive catalog of zebrafish behavior 1.0 and beyond. Zebrafish 2013, 10, 70-86.

(22) Oshima, Y.; Kang, I. J.; Kobayashi, M.; Nakayama, K.; Imada, N.; Honjo, T. Suppression of sexual behavior in male Japanese medaka (Oryzias latipes) exposed to $17 \beta$-estradiol. Chemosphere 2003, 50, 429-436.

(23) Saglio, P.; Trijasse, S. Behavioral responses to atrazine and diuron in goldfish. Arch. Environ. Contam. Toxicol. 1998, 35, 484-491.

(24) Groh, K. J.; Carvalho, R. N.; Chipman, J. K.; Denslow, N. D.; Halder, M.; Murphy, C. A.; Roelofs, D.; Rolaki, A.; Schirmer, K.; Watanabe, K. H. Development and application of the adverse outcome pathway framework for understanding and predicting chronic toxicity: I. Challenges and research needs in ecotoxicology. Chemosphere 2015, 120, 764-777.

(25) Rihel, J.; Schier, A. F. Behavioral screening for neuroactive drugs in zebrafish. Dev. Neurobiol. 2012, 72, 373-385.

(26) Jarema, K. A.; Hunter, D. L.; Shaffer, R. M.; Behl, M.; Padilla, S. Acute and developmental behavioral effects of flame retardants and related chemicals in zebrafish. Neurotoxicol. Teratol. 2015, 52, 194209.

(27) MacPhail, R. C.; Brooks, J.; Hunter, D.; Padnos, B.; Irons, T.; Padilla, S. Locomotion in larval zebrafish: influence of time of day, lighting and ethanol. Neurotoxicology 2009, 30, 52-58.

(28) Weis, J. S.; Weis, P. Effects of embryonic exposure to methylmercury on larval prey-capture ability in the mummichog Fundulus heteroclitus. Environ. Toxicol. Chem. 1995, 14, 153-156.

(29) Weis, J. S.; Khan, A. A. Effects of mercury on the feeding behavior of the mummichog, Fundulus heteroclitus from a polluted habitat. Mar. Environ. Res. 1990, 30, 243-249.

(30) Fjeld, E.; Haugen, T.; Vøllestad, L. Permanent impairment in the feeding behavior of grayling (Thymallus thymallus) exposed to methylmercury during embryogenesis. Sci. Total Environ. 1998, 213, 247-254.

(31) Lacroix, A.; Hontela, A. A comparative assessment of the adrenotoxic effects of cadmium in two teleost species, rainbow trout, Oncorhynchus mykiss, and yellow perch, Perca flavescens. Aquat. Toxicol. 2004, 67, 13-21.

(32) Mora-Zamorano, F. X.; Svoboda, K. R.; Carvan, M. J., III The Nicotine-Evoked Locomotor Response: A Behavioral Paradigm for
Toxicity Screening in Zebrafish (Danio rerio) Embryos and Eleutheroembryos Exposed to Methylmercury. PLoS One 2016, 11, No. e0154570.

(33) Mansueti, A. J. Early development of the yellow perch, Perca flavescens. Chesapeake Sci. 1964, 5, 46-66.

(34) Heyer, C. J.; Miller, T. J.; Binkowski, F. P.; Caldarone, E. M.; Rice, J. A. Maternal effects as a recruitment mechanism in Lake Michigan yellow perch (Perca flavescens). Can. J. Fish. Aquat. Sci. 2001, $58,1477-1487$.

(35) Smith, L. E.; Carvan, M. J.; Dellinger, J. A.; Ghorai, J. K.; White, D. B.; Williams, F. E.; Weber, D. N. Developmental selenomethionine and methylmercury exposures affect zebrafish learning. Neurotoxicol. Teratol. 2010, 32, 246-255.

(36) Weber, D. N.; Connaughton, V. P.; Dellinger, J. A.; Klemer, D.; Udvadia, A.; Carvan, M. J. Selenomethionine reduces visual deficits due to developmental methylmercury exposures. Physiol. Behav. 2008, 93, 250-260.

(37) Carvan, M. J., III; Kalluvila, T. A.; Klingler, R. H.; Larson, J. K.; Pickens, M.; Mora-Zamorano, F. X.; Connaughton, V. P.; SadlerRiggleman, I.; Beck, D.; Skinner, M. K. Mercury-induced epigenetic transgenerational inheritance of abnormal neurobehavior is correlated with sperm epimutations in zebrafish. PLoS One 2017, 12, No. e0176155.

(38) Nam, D.-H.; Basu, N. Rapid methods to detect organic mercury and total selenium in biological samples. Chem. Cent. J. 2011, 5, 3.

(39) Ulhaq, M.; Örn, S.; Carlsson, G.; Morrison, D. A.; Norrgren, L. Locomotor behavior in zebrafish (Danio rerio) larvae exposed to perfluoroalkyl acids. Aquat. Toxicol. 2013, 144-145, 332-340.

(40) Emran, F.; Rihel, J.; Dowling, J. E. A behavioral assay to measure responsiveness of zebrafish to changes in light intensities. J. Visualized Exp. 2008, No. e923.

(41) Cordelières, F. P. Manual Tracking; Institut Curie: Orsay, France, 2005.

(42) Schneider, C. A.; Rasband, W. S.; Eliceiri, K. W. NIH Image to ImageJ: 25 years of image analysis. Nat. Methods 2012, 9, 671-675. 